\title{
DEVELOPMENT OF SHORT FORM QUESTIONNAIRES FOR THE ASSESSMENT OF WORK CAPACITY IN CARDIOVASCULAR REHABILITATION PATIENTS
}

\author{
ANNE HASCHKE ${ }^{1}$, BIRGIT ABBERGER ${ }^{1}$, MARKUS WIRTZ², JÜRGEN BENGEL ${ }^{1}$, and HARALD BAUMEISTER ${ }^{1,3}$ \\ ${ }^{1}$ University of Freiburg, Freiburg, Germany \\ Department of Rehabilitation Psychology and Psychotherapy, Institute of Psychology \\ ${ }^{2}$ University of Education, Freiburg, Germany \\ Department of Research Methods, Institute of Psychology \\ ${ }^{3}$ University of Freiburg, Freiburg, Germany \\ Department of Medical Psychology and Medical Sociology, Medical Faculty
}

\begin{abstract}
Objectives: Prevention of job loss is an essential objective of cardiovascular rehabilitation. However, comprehensive and economic diagnostic instruments on work limitations are missing. The present study describes development of short form questionnaires from 2 domains of the WCIB-Cardio item banks for the assessment of work capacity in cardiovascular rehabilitation patients. Materials and Methods: 283 cardiovascular rehabilitation patients were recruited from 14 German rehabilitation clinics. Based on the WCIB-Cardio with the domains of cognitive and physical work capacity, we developed a short form for both domains. Item selection criteria were content coverage, content appropriateness, internal consistency reliability $(\geq 0.8)$. We used correlation of person location scores of the short forms with person location scores of the full item banks to examine the extent of measurement precision. Results: For each domain of the WCIB-Cardio a short form was developed (cognitive work capacity - 14 items; physical work capacity 7 -items). In both domains psychometric properties were good (person separation index: cognitive work capacity - 0.80; physical work capacity - 0.80). Correlation measures of the short form with the full item banks showed a high accordance of person locations for both domains (cognitive work capacity: $r=0.97$; physical work capacity: $r=0.95)$. Conclusions: The calibrated instrument WCIB-Cardio provides the possibility to develop short form questionnaires with high psychometric quality. These short forms make it possible to monitor patient's work capacity in cardiovascular rehabilitation settings in a more economical way.
\end{abstract}

Key words:

Item response theory, Work capacity evaluation, Cardiovascular patients, Item bank, Short form

\section{INTRODUCTION}

Maintenance and improvement of work capacity in addition to physical recovery is one of the prior aims of cardiovascular rehabilitation. However, psychometrically sound and economical assessment of work capacity is challenging. Observation of patients in their working environment, estimating the fitting of the patient's work capacities and job demands, is viewed as the gold standard for the assessment of work capacity [1,2]. However, in the light of the personal and time-consuming procedure of this attempt it is hardly applicable in daily clinical practice.

This work was supported by the Illa and Werner Zarnekow-Foundation (grant number T225-18.152).

Received: November 21, 2012. Accepted: October 7, 2013.

Corresponding author: A. Haschke, Department of Rehabilitation Psychology and Psychotherapy, Engelbergerstr. 41, 79085 Freiburg, Germany (e-mail: anne.haschke@ psychologie.uni-freiburg.de). 
Self-reports such as the Work Limitations Questionnaire [3], the Work Ability Index [4] and the Angina Related Limitations at Work Questionnaire, [5] are used as a more economical way to assess work capacity [6]. On the other hand, self-reports are viewed as psychometrically limited [7,8]. Most of these self-reports are developed within classical test theory (CTT). Two major psychometric restrictions of CTT are: dependency of item statistics on the test person sample and test dependency on the scores [9]. To overcome these psychometric shortcomings one could base development of self-report questionnaires on the methods of item response theory (IRT) such as the Rasch model [10,11].

The IRT provides a model based measurement, which is based on the assumption of dependency of a person's answers (manifest variable) on both the underlying ability of the person (latent variable) and difficulty of the specific item [12]. Advantages of IRT models in contrast to CTT include: local stochastic independency and sample independency [9]. Another requirement of IRT models to make suggestions concerning the level of ability of a person to work is the assumption of unidimensionality, i.e. that all items assess the same latent dimension, for example "work capacity" $[10,12]$.

Although psychometric advantages of the instruments, developed in the framework of IRT seem to be promising, to the best of our knowledge there is no Rasch-based instrument for work capacity assessment in cardiovascular rehabilitation patients. Hence, we developed the WCIBCardio, which consists of two IRT-based calibrated item banks for the assessment of cognitive and physical work capacity with 20 respectively 18 items [13]. As a next step, the WCIB-Cardio allows the development of a psychometrically sound and economical short form version the WCIB-Cardio-SF.

The aim of the present study was to develop the WCIBCardio-SF, which will offer an economical way to assess and monitor patients' ${ }^{\prime}$ work capacity in cardiovascular rehabilitation.

\section{METHODS}

\section{Sample/Participants}

Patients were enrolled in 14 German rehabilitation centers. The patients with diagnosis of ischaemic heart diseases (ICD10: I20-I25), other forms of heart diseases (ICD10: I30-52) or hypertensive diseases (ICD10: I1015) were included in the study. Measurements were restricted to cardiac patients as one of the largest groups in medical rehabilitation [14]. Patients with acute intoxication, dementing syndromes or inappropriate German language skills were excluded from the study. Total sample consisted of 283 patients, who were gainfully employed at the time of data collection. The patients gave their informed consent prior to attending the study. The included patients were mainly male $(81.3 \%)$ and married $(72.1 \%)$ with an average age of 53 years. $55.8 \%$ of the study group had ischemic heart disease, $13.8 \%$ another heart disease and $17.7 \%$ hypertension. $12.4 \%$ of the patients were diagnosed with 2 different cardiovascular diseases (I20-25 and I30-52). Majority of them were white collar workers $(68.9 \%)$, followed by blue collar workers $(19.4 \%)$ and self-employed (11\%). Characteristics of the study sample are presented in Table 1. According to the statistical data concerning cardiac patients of the German statutory pension insurance scheme (mean age: 52.2; men: 83.84\%) [14] and high number of participating clinics, this sample can be seen as representative.

\section{Instrument}

In order to develop short forms for clinical use and research purposes, we used a comprehensive instrument (WCIB-Cardio) for evaluation of work capacity. To develop an item bank, first, an item pool - a collection of items within the same domain - was needed. By screening existing literature and collecting items of a certain domain like "work capacity", as well as constructing new items building of an item pool was accomplished. Having checked the 
Table 1. Characteristics of the study population

\begin{tabular}{|c|c|}
\hline Variables & $\begin{array}{c}\text { Respondents } \\
(\%)\end{array}$ \\
\hline Age (years), $\mathrm{M} \pm \mathrm{SD}(\mathrm{N}=281)$ & $53.0 \pm 6.7$ \\
\hline \multicolumn{2}{|l|}{$\operatorname{Sex}(N=283)$} \\
\hline male & 81.3 \\
\hline \multicolumn{2}{|l|}{ Family status (N = 283) } \\
\hline unmarried & 7.9 \\
\hline in a relationship & 8.9 \\
\hline married & 72.8 \\
\hline divorced/separated & 8.6 \\
\hline widowed & 1.8 \\
\hline \multicolumn{2}{|l|}{ Occupation $(\mathrm{N}=283)$} \\
\hline a blue collar worker & 19.4 \\
\hline a white collar worker & 66.1 \\
\hline a public servant & 2.8 \\
\hline a self employed & 11.0 \\
\hline other & 0.7 \\
\hline \multicolumn{2}{|l|}{ Mental comorbidities $(\mathrm{N}=283$ ) } \\
\hline 0 & 74.9 \\
\hline 1 & 24.7 \\
\hline 2 & 0.4 \\
\hline \multicolumn{2}{|l|}{ Somatic comorbidities ( $\mathrm{N}=283$ ) } \\
\hline 0 & 14.5 \\
\hline 1 & 32.9 \\
\hline 2 & 26.5 \\
\hline$\geq 3$ & 26.1 \\
\hline \multicolumn{2}{|l|}{ Education $(\mathrm{N}=269)$} \\
\hline 9 years & 34.6 \\
\hline 10 years & 30.1 \\
\hline$>10$ years & 34.9 \\
\hline none & 0.4 \\
\hline Sick leave days (SD) $(\mathrm{N}=277)$ & 35.8 \\
\hline \multicolumn{2}{|l|}{ Diagnosis $(\mathrm{N}=283)$} \\
\hline $\mathrm{I} 10$ & 17.7 \\
\hline $\mathrm{I} 20-25$ & 56.0 \\
\hline $\mathrm{I} 30-52$ & 13.8 \\
\hline $\mathrm{I} 20-25$ and I30-52 & 12.5 \\
\hline
\end{tabular}

M - mean; SD - standard deviation.

I10 - hypertensive diseases.

I20-25- ischaemic heart diseases.

I30-52 - other forms of heart disease. items for relevance and calibrating them through procedures as Rasch analysis an item bank was build [15]. The WCIB-Cardio consists of 2 item banks for the domains of cognitive (CWC: 20 items) and physical work capacity (PWC: 18 items).

Development of each item bank involved an exploratory factor analysis and separate Rasch analyses of both domains [13]. The patients were asked to rate their capacity to accomplish certain tasks in the last 4 weeks of their work. Response options ranged from "without difficulties" to "impossible" on a 5-point Likert-scale. Additionally, there was a possibility to choose „not applicable“, in the case of activities not present in particular job. The original German version of the WCIB-cardio is available on request from the corresponding author.

Primary diagnosis, comorbid diseases and physician's evaluation of work capacity were extracted from the medical records. Socio-demographic variables (i.e. age, family status, education) and disease-specific variables (intensity of pain and subjective limitations due to illness) were assessed by self-reports of the patients.

\section{Analyses}

The WCIB-Cardio-SF was developed for both domains separately. To achieve the best possible composition of items a one by one deletion process starting with the full item banks was performed. Item selection criteria were: item location, item content and satisfactory internal consistency reliability. To assure a wide coverage range of work capacity, we selected items with a wide location range. Furthermore, with regard to content appropriateness we selected items with respect to a broad variety of different activities in order to describe the domain of work capacity properly.

To avoid intense loss of reliability we chose a limit of the reliability value at $\geq 0.8$. To examine measurement precision of the 2 short form versions we calculated Pearson correlations of the theta values (person 
parameter) of each short form with the full item bank using PASW [16]. Person-item distribution graphics were used to monitor the concordance of the ability range of the sample and the ability range covered by the items of the short forms.

Subsequently, in order to examine model fit for each short form, we conducted a separate Rasch analysis for each domain, using RUMM2030 [17]. The following procedures were previously described in detail elsewhere [13]. For better understanding, we briefly mention Rasch quality criteria for adequate fitting of the model to the underlying data $[18,19]$.

\section{Ordered item thresholds}

If there is an increase of the trait value for each answer category in the 5-point Likert-scale items are called "ordered" [18]. If thresholds were disordered, adjacent categories were merged.

Global and individual fitting of the data

Global fitting: RUMM2030 provides 2 item-person interaction statistics requiring values approximately to 0 as the perfect fit with a standard deviation of 1 [18] and an itemtrait interaction statistics. In this case $\mathrm{Chi}^{2}$-values should be non-significant, indicating a hierarchical ordering of items and persons.

Individual fitting: RUMM2030 provides $\mathrm{Chi}^{2}$-values and residual statistics to test for misfit of items. Residual values from -2.5 to 2.5 and $\mathrm{Chi}^{2}$-values $>0.05$ are required [20].

Local dependence

Local dependence is defined by linked residuals of items [18]. This was proved by examining the residual correlation matrix for linked items with values $>0.30$.

Internal consistency reliability

This value is equivalent to Chronbach's $\alpha$ [18]. Assessment instruments with PSI (person separation index) values from 0.7 to 0.8 can be used for group comparison, values above 0.85 can be used for individual testing [18].

Final unidimensionality of items was tested following the procedure by Smith (2002) [19]. We divided items into 2 groups (items with positive and negative loadings of the first factor of the principal component analysis of residuals (PCA)) and conducted t-tests. The number of significant t-tests should not exceed $5 \%$. In a binomial test, a confidence interval for the observed number of significant tests was calculated. If this output exceeds the $5 \%$ of the expected value, the scale is considered to be unidimensional [19].

To monitor test fairness of the single items, existence of Differential Item Functioning (DIF) was assessed. DIF is a significant deviation observed from the expected responses across class intervals [21]. If an item shows DIF, the given response leads not exclusively to the latent ability, but to other factors as well [22]. DIF was examined by the use of ANOVA of the person item deviation residuals with person factors and class intervals as factors $[12,23]$. We conducted DIF analyses for age (under 50/51-60/over 61 years), gender (male/female), education (none/9 years/10 years/over 10 years) indication (ICD10: I10; ICD10: I20-25; ICD10: I30-52; ICD10: I20-25 and I30-52), intensity of pain (none/mild/strong) and subjective limitations due to illness (none/mild/middle/strong).

\section{RESULTS}

\section{Cognitive Work Capacity (CWC-SF)}

After reducing the item bank to a short form by deleting items one by one, 14 items remained. All category thresholds were ordered. The overall model fit was good with a total item trait interaction value of $\mathrm{p}=0.57 ;\left(\mathrm{Chi}^{2}=39.82\right.$; total degree of freedom $=42$ ). Mean overall residual fit of items was $-0.2(\mathrm{SD}=0.88)$; mean overall residual fit of persons was -0.25 ( $\mathrm{SD}=0.93)$. No item showed misfit (residual values \pm 2.5 ), or residual correlations $>0.30$. 


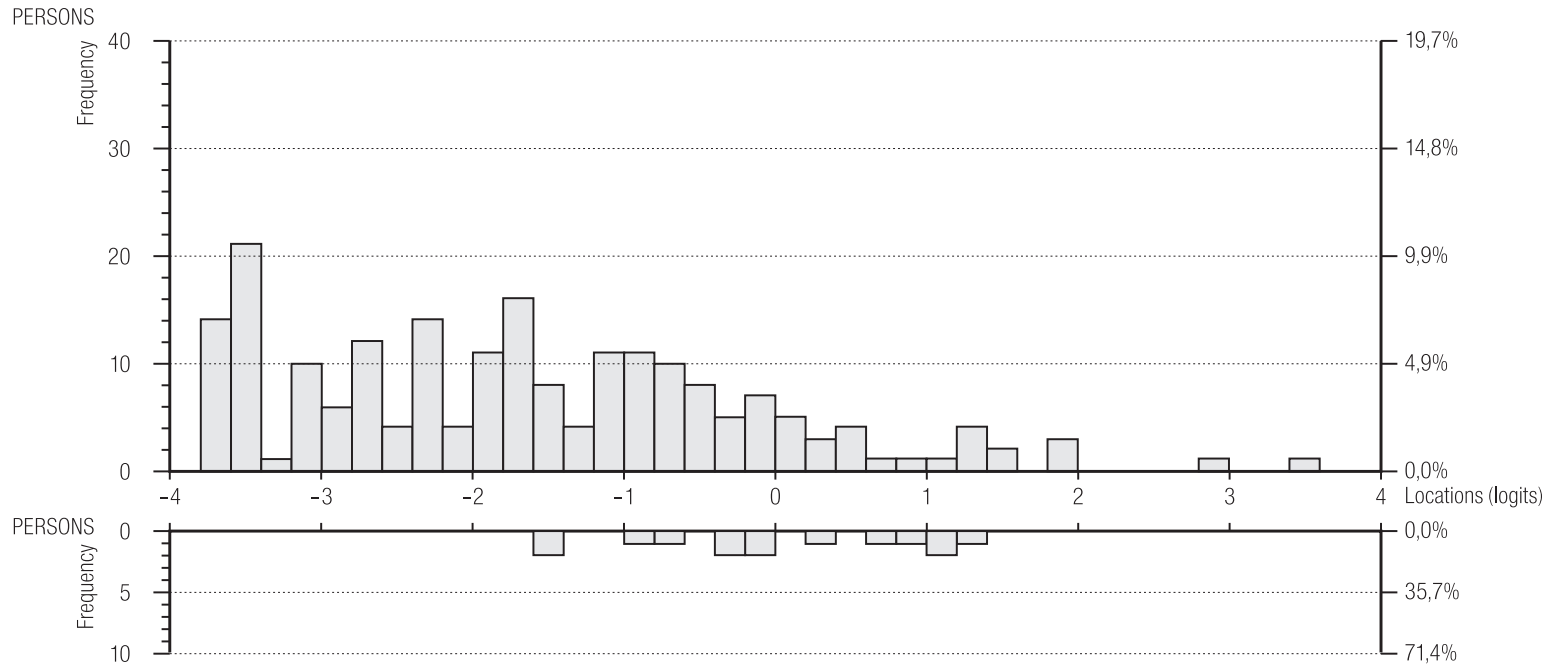

Fig. 1. Person-item location distribution (CWC-SF)

The remaining items showed a PSI of 0.80 . Unidimensionality was confirmed with $2.67 \%$ of significant t-tests.

The binomial test showed non-significant p-values which supports the assumption of unidimensionality of the scale. Due to DIF analyses, no item with DIF could be detected. Person-item distribution showed left skewed distribution of patients (mean location of persons: -2.28 ; $\mathrm{SD}=1.76$ ). With an item location range from -1.54 to 1.31 , and item thresholds ranging from -2.84 to 3.86 a broad range on the continuum of cognitive work capacity is described (see Figure 1 and Table 2). In comparison with item locations of the full item bank (-1.57-1.35), almost the full item location range could be preserved. Correlation between the full item bank and the CWC-SF was very good with a value of $r=0.97$.

Table 2. Short forms of the cognitive work capacity (CWC) and the physical work capacity (PWC) domains

\begin{tabular}{clrrrr}
\hline Item & \multicolumn{1}{c}{$\begin{array}{c}\text { How many times during the past } 4 \text { weeks prior to your treatment, } \\
\text { when you were still working, were you able... }\end{array}$} & $\begin{array}{c}\text { Answer } \\
\text { structure }\end{array}$ & $\begin{array}{r}\text { Fit residual } \\
\text { of items }\end{array}$ & $\begin{array}{c}\mathrm{Chi}^{2} \\
\text { (prob) }\end{array}$ & $\begin{array}{c}\text { Location } \\
\text { (SE) }\end{array}$ \\
\hline CWC & & & & & \\
A14 & to give the same job performance than before your illness & 01234 & -0.18 & $0.61(0.89)$ & $-1.50(0.13)$ \\
A16 & to deal successfully with new assignments and challenges & 01234 & -0.87 & $3.23(0.36)$ & $-0.88(0.14)$ \\
A05 & to complete your assignments within your schedule & 01233 & 0.10 & $0.49(0.92)$ & $-0.23(0.13)$ \\
B12 & to apprehend complex assignments & 01223 & -0.01 & $0.70(0.87)$ & $-0.38(0.18)$ \\
B19 & to work concentrated despite distracting environment & 01233 & -1.07 & $5.76(0.12)$ & $-0.77(0.14)$ \\
B28 & to adjust your mistakes at work as you used to & 01222 & -0.20 & $1.42(0.70)$ & $1.13(0.19)$ \\
B29 & to develop new ideas or solutions at work & 01233 & -0.19 & $5.45(0.14)$ & $0.64(0.17)$ \\
B02 & to concentrate on your work & 01233 & -1.46 & $4.69(0.20)$ & $0.40(0.14)$ \\
B04 & to work without getting confused & 01223 & -0.99 & $2.15(0.54)$ & $-0.05(0.14)$ \\
B17Y & to read a longer text attentively & 01234 & 1.38 & $3.35(0.34)$ & $1.15(0.18)$ \\
E01 & to arrive on schedule at your workplace & 01234 & -0.36 & $4.14(0.25)$ & $1.31(0.36)$ \\
E04 & to complete the working hours that are customary for your employment & 01111 & -0.58 & $4.50(0.21)$ & $-0.20(0.25)$ \\
E07 & to organize your workload & 01111 & -0.09 & $1.03(0.79)$ & $0.93(0.16)$ \\
F07 & to know your limits at work & 01233 & 1.77 & $2.30(0.51)$ & $-1.54(0.15)$ \\
\hline
\end{tabular}


Table 2. Short forms of the cognitive work capacity (CWC) and the physical work capacity (PWC) domains - cont.

\begin{tabular}{|c|c|c|c|c|c|}
\hline Item & $\begin{array}{l}\text { How many times during the past } 4 \text { weeks prior to your treatment, } \\
\text { when you were still working, were you able... }\end{array}$ & $\begin{array}{c}\text { Answer } \\
\text { structure }\end{array}$ & $\begin{array}{l}\text { Fit residual } \\
\text { of items }\end{array}$ & $\begin{array}{c}\mathrm{Chi}^{2} \\
\text { (prob) }\end{array}$ & $\begin{array}{l}\text { Location } \\
(\mathrm{SE})\end{array}$ \\
\hline \multicolumn{6}{|l|}{ PWC } \\
\hline $\mathrm{C} 11$ & $\begin{array}{l}\text { to bend down at work to lift a heavy object (e.g. a package with paper, } \\
\text { a bucket full of water) }\end{array}$ & 01223 & -1.22 & $5.50(0.14)$ & $0.01(0.16)$ \\
\hline $\mathrm{C} 14$ & to stretch at work (e.g. to reach things on high shelves) & 01122 & -1.09 & $5.1(0.16)$ & $0(0.13)$ \\
\hline $\mathrm{C} 16$ & to use tools or instruments (with your hands) at work & 01234 & -0.49 & $1.44(0.70)$ & $2.06(0.22)$ \\
\hline $\mathrm{C} 04$ & to get to all the rooms and places at your workplace you needed to go to & 01122 & 0.20 & $3.85(0.28)$ & $1.18(0.20)$ \\
\hline $\mathrm{C} 07$ & to endure lopsided physical exposure & 01234 & 0.72 & $1.30(0.73)$ & $-0.49(0.15)$ \\
\hline $\mathrm{C} 08 \mathrm{Z}$ & to be upright at work for several hours a day & 01234 & 1.01 & $2.20(0.53)$ & $-1.51(0.15)$ \\
\hline $\mathrm{C} 28 \mathrm{Y}$ & $\begin{array}{l}\text { to complete an assignment at work that requires lifting your arms above } \\
\text { the head for a longer time (e.g. for changing a light bulb) }\end{array}$ & 01233 & -0.61 & $0.83(0.84)$ & $-1.24(0.14)$ \\
\hline
\end{tabular}

Prob - probability; SE - standard error.

\section{Physical Work Capacity (PWC-SF)}

After excluding items one by one 7 of the original 18 items remained. One item needed to be rescored (Item C11: "...to bend down at work to lift a heavy object (e.g. a package with paper, a bucket full of water")). The overall model fit was good with a total item trait interaction value of $\mathrm{p}=0.5 ;\left(\mathrm{Chi}^{2}=20.23\right.$; total degree of freedom: 21). Mean overall residual fit of items was $-0.21(\mathrm{SD}=0.87)$; mean overall residual fit of persons was $-0.35(\mathrm{SD}=0.84)$. No item showed misfit (residual values: \pm 2.5 ), or residual correlations $>0.30$. The remaining items showed a PSI value of 0.80 . Unidimensionality was confirmed with $4.00 \%$ significant t-tests. The binomial test showed non-significant $\mathrm{p}$-values which supports the assumption of unidimensionality of the scale. As for the cognitive work capacity domain, no item with DIF could be detected. Person-item distribution showed left skewed distribution of patients (mean

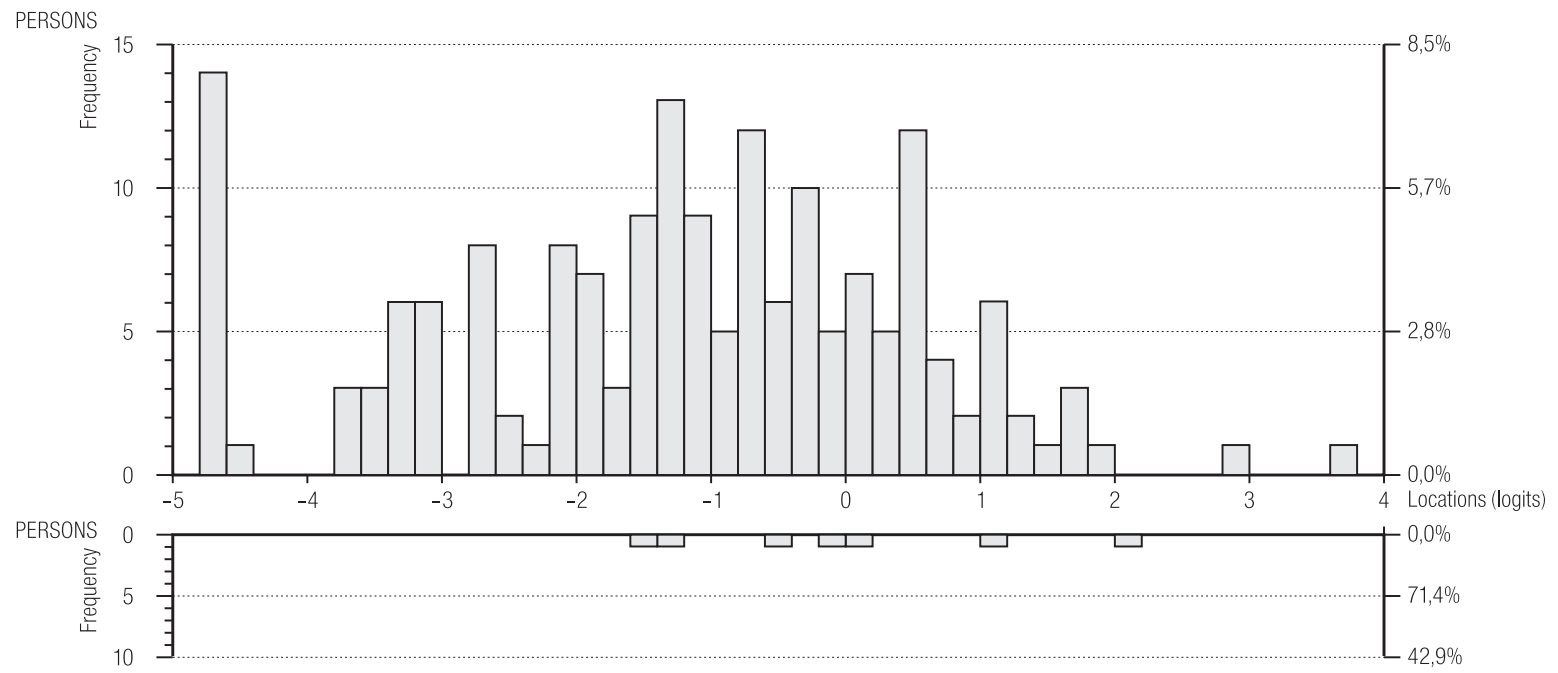

Fig. 2. Person item location distribution (PWC-SF) 
location of persons: $0-2.55$; $\mathrm{SD}=2.60$ ). With an item range from $0-1.51$ to 2.06 , and item thresholds ranging from $0-4.56$ to 3.70 a broad range on the continuum of cognitive work capacity is described (see Figure 2 and Table 2). In comparison with item locations of the full item bank (-1.74-2.22), almost the full item location range could be preserved. Correlation between the full item bank and the PWC-SF was very good with a value of $r=0.95$.

\section{DISCUSSION}

The aim of the present study was to develop a short form questionnaire for work capacity assessment based on 2 calibrated item banks. Basing on the WCIB-Cardio with its 2 domains of cognitive and physical work capacity we were able to develop the WCIB-Cardio-SF with high psychometric properties. By choosing a step by step items deletion process a high reliability was achieved. Measurement precision was confirmed with very good correlation measures between the short form domains of cognitive and physical work capacity and the full item banks of both domains.

A diminution of only 0.07 logits (CWC) and 0.39 logits (PWC) in item location ranges of the WCIB-Cardio-SF in contrast to the full item banks indicates a comprehensive work capacity evaluation with a broad content coverage in both domains. In the domain of cognitive work capacity, a deletion of 6 items led to developing a final version comprising 14 items.

Further reduction of items was not recommendable with regard to substantially declining PSI values. In the domain of physical work capacity, a reduction of 11 items to a final version with 7 items was possible. By this remarkable reduction of $61 \%$, in comparison with the full item bank, the WCIB-Cardio-SF provides a highly economical way of evaluating physical work capacity, while maintaining psychometric quality.
A larger number of items in the cognitive work capacity domain compared to the physical work capacity domain might be indicative of a higher complexity of the construct of cognitive work capacity. Furthermore, we ensured test fairness of the WCIB-Cardio-SF by conducting DIF analyses not only for age and gender, but also for the parameters such as: education, indication, pain intensity and subjective limitations due to illness. For all parameters the WCIB-Cardio-SF proved to be free of DIF and thus, can be considered as a test fair instrument.

The WCIB-Cardio-SF is of similar length compared to other work capacity measurement instruments such as the Work Limitations Questionnaire (WLQ) [3] and the Angina Related Limitations at Work Questionnaire [5]. The 48 items of the WLQ measure 4 dimensions (time demands, physical demands, mental interpersonal demands and output demands) of work capacity, whereas the Angina Related Limitations at Work Questionnaire includes 17 specific work activities. The WCIB-Cardio-SF with its 2 domains of "cognitive" and "physical" work capacity covers similar aspects of work capacity. Furthermore, the WCIB-CardioSF has been tested for unidimensionality and thus, allows a more psychometrically sound assessment of self-reported work capacity.

The WCIB-Cardio-SF might be used as a paper-pencil version or as a computer based version. The advantageous feature of a computer based instrument is the possibility to disseminate the results quickly to all the relevant persons in a clinic such as treating physicians or vocational counselors. Comparing computer based assessment and paper-pencil methods Eisen et al. (2004) found high correlations between these methods, indicating validity of computerized testing [24]. A computer based version of the WCIB-Cardio-SF would furthermore provide the possibility to integrate the WCIB-Cardio-SF in a battery of computer (adaptive) instruments such as the RehaCATCardio [25-27]. 


\section{Limitations}

Firstly, person-item distribution figures show that most of the patients evaluate themselves as lightly burdened in both domains of work capacity due to their cardiovascular disease. A replication study with a larger sample size or an oversampling of patients at risk of work incapability would further increase the psychometrical standard of the WCIB-Cardio-SF. Secondly, at this point of development, WCIB-Cardio short forms are designed for the use in cardiovascular patients only. A calibration of the WCIB-Cardio in other than cardiovascular populations (e.g. general population, oncological patients) would further increase the generalizability of the WCIB-Cardio-SF.

Finally, there could be a potential bias of the retrospective evaluation of work capacity to evaluate actual and prospective work capacity. Further studies are needed to clarify the power of the WCIB-Cardio-SF to predict the patients' return to work.

\section{CONCLUSIONS}

On the basis of a calibrated instrument, the WCIBCardio short form constitutes an economical instrument to monitor patients' work capacity in cardiovascular rehabilitation settings. This short form may be used for screening purposes and can assist physicians to identify patients at risk of work incapacity at an early stadium of the rehabilitation process. Based on the results, physicians can adapt their treatment in a more specific way to the patients' needs in terms of work related support (i.e. tailored exercise; cognitive behavioral strategies; vocational counseling). Further studies are needed to clarify the power of the WCIB-Cardio-SF to predict the patients' return to work as well as the agreement between patients' and physicians' evaluation of work capacity. Finally, a calibration of the WCIB-cardio SF in other than cardiovascular populations would further increase the generalizability of the WCIB-cardio SF.

\section{ACKNOWLEDGMENTS}

We would like to thank all the participating patients and the study centers: Clinic Wingertsberg, Park Clinic Lazariterhof/ Clinic Baden, Schuechtermann-Clinic, Rehabilitation Centre Bayerisch Gmain, Gollwitzer-Meier-Clinic, Median Clinic Bad Oeynhausen, Kerckhoff-Rehabilitation Centre, Clinic Dr. Voetisch, SRH Health Centre Bad Wimpfen, KMG Clinic Silbermuehle, Clinic Koenigsfeld, Drei-Burgen-Clinic, Clinic Wehrawald and Clinic Schwabenland.

\section{REFERENCES}

1. Chamberlain MA. Work, disability and rehabilitation: making the best job of it. Clin Med. 2007;7(6):603-6.

2. Sandqvist JL, Henriksson CM. Work functioning: A conceptual framework. Work. 2004;23(2):147-57.

3. Lerner DJ, Amick III BC, Rogers WH, Malspeis S, Bungay K, Cynn D. The Work Limitations Questionnaire. Med Care. 2001;37(1):72-85.

4. Tuomi K. Work Ability index. 2nd revised ed. Helsinki: Finnish Institute of Occupational Health; 1998.

5. Lerner DJ, Amick III BC, Malspeis S, Rogers WH, Gomes DRJ, Salem DN. The Angina-related Limitations at Work Questionnaire. Qual Life Res. 1998;7(1):23-32.

6. Serra C, Cruz Rodriguez M, Delclos GL. Criteria and methods used for the assessment of fitness for work: a systematic review. Occup Environ Med. 2007;64:304-12, http://dx.doi. org/10.1136/oem.2006.029397

7. Innes E. Reliability and validity of functional capacity evaluations: An update. Int J Disabil Manag Res. 2006;1(1):135-48.

8. Innes E, Straker L. Reliability of work related assessments. Work. 1999;13(2):107-24.

9. Hambleton RK. Emergence of item response modeling in instrument development and data analysis. Med Care. 2000;38(9 Suppl):II60-5.

10. Bond TG, Fox CM. Applying the Rasch model: Fundamental measurement in the human sciences. Mahwah, NJ: Erlbaum; 2001. 
11. Rasch G. Probabilistic models for some intelligence and attainment tests. Copenhagen: Danish Institute for Educational Research; 1960.

12. Embretson SE, Reise SP, editors. Item response theory for psychologists. Mahwah: Lawrence Erlbaum Associates; 2000.

13. Haschke A, Abberger B, Müller E, Wirtz M, Bengel J, Baumeister H. Calibration of an item bank for work capacity in cardiological rehabilitation patients. Eur J Prev Cardiol. 2013;20(5):80716, http://dx.doi.org/10.1177/2047487312447911.

14. DRV Hrsg. Statistik der deutschen Rentenversicherung. Berlin: Deutsche Rentenversicherung Bund; 2011.

15. Wright BD, Bell SR. Item banks: What, why, how. J Educ Measur. 1984;21(4):331-45.

16. SPSS Inc. Predictive Analysis SoftWare (PASW), Version 18. Chicago: SPSS Inc.; 2009.

17. Rumm 2030. Perth: RUMM Laboratory; 2009.

18. Tennant A, Conaghan PG. The Rasch measurement model in rheumatology: What is it and why use it? When should it be applied, and what should one look for in a Rasch paper? Arthrit Rheum. 2007;57(8):1358-62, http://dx.doi.org/10.1002/art.23108.

19. Smith EV. Detecting and evaluating the impact of mulitdimensionality using item fit statistics and principal component analysis of residuals. J Appl Measurement. 2002;(3):205-31.

20. Tennant A, Penta M, Tesio L, Grimby G, Thonnard J-L, Slade A et al. Assessing and adjusting for cross-cultural validity of impairment and activity limitation scales through Differential Item Functioning within the framework of the Rasch model. Med Care. 2004;42:37-48, http://dx.doi. org/10.1097/01.mlr.0000103529.63132.77.
21. Holland P, Wainer H. Differential item functioning. New York: Erlbaum; 1993.

22. Fleishman JA, Spector WD, Altman BM. Impact of differential item functioning on age and gender differences in functional disability. J Gerontol. 2002;57B(5):275-84.

23. Teresi JA, Kleinman M, Ocepek-Welikson K. Modern psychometric methods for detection of differential item functioning: application to cognitive assessment measures. Stat Med. 2000;19:1651-83.

24. Eisen SV, Toche-Manley LL, Grissom GR. Computer-administrated versus paper-and-pencil mental health surveys. Psych Serv. 2004;55(11):1316-7.

25. Abberger B, Haschke A, Krense C, Bengel J, Wirtz M, Baumeister $\mathrm{H}$. The calibrated, unidimensional anxiety item bank for cardiovascular patients provided the basis for anxiety assessment in cardiovascular rehabilitation patients. J Clin Epidemiol. 2013;66(8):919-27, http://dx.doi.org/10.1016/ j.jclinepi.2012.08.009.

26. Forkmann T, Kroehne U, Boecker M, Wirtz M, Norra C, Baumeister $\mathrm{H}$ et al. Adaptive Screening for Depression - Recalibration of an item bank for the assessment of Depression in persons with mental and somatic diseases and evaluation in a simulated Computer-adaptive Test environment. J Psychosom Res. 2013;75(5):437-43, http://dx.doi. org/10.1016/j.jpsychores.2013.08.022.

27. Baumeister H, Abberger B, Haschke A, Bengel J, Wirtz M. Development and calibration of an item bank for the assessment of activities of daily living in cardiovascular patients using Rasch analysis. Health Qual Life Outcomes. 2013,11:133, http://dx.doi.org/10.1186/1477-7525-11-133.

This work is available in Open Access model and licensed under a Creative Commons Attribution-NonCommercial 3.0 Poland License - http://creativecommons.org/ licenses/by-nc/3.0/pl/deed.en. 